\title{
Case Report: Odontoid Fracture Anderson and D'Alonzo Type II Associated with Central Cord Syndrome
}

\author{
William Wiryawan $^{1 \star}$, Otman Siregar², \\ Pranajaya Dharma Kadar ${ }^{2}$, Heru Rahmadhany ${ }^{2}$, Benny ${ }^{3}$ \\ ${ }^{1}$ Resident of Orthopaedic and Traumatology, Faculty of Medicine, Universitas \\ Sumatera Utara, H. Adam Malik Hospital Medan, Indonesia \\ ${ }^{2}$ Consultant of Orthopaedic and Traumatology, Spine Division, Faculty of Medicine, \\ Universitas Sumatera Utara, H. Adam Malik Hospital Medan, Indonesia \\ ${ }^{3}$ Staff of Orthopaedic and Traumatology, Spine Division, Faculty of Medicine, \\ Universitas Sumatera Utara, H. Adam Malik Hospital Medan, Indonesia
}

\begin{abstract}
Patient presented with paraparesis of the arm after sustaining a motorvehicle accident. XRay Cervical showed type II odontoid fracture. Tetraparesis has been reported to be associated with fracture of axis and/ or atlas and acute CCS has rarely been associated with the fractures. However, this case illustrated patient with central cord syndrome asscociated with odontoid fracture. MRI of the cervical spine has revealed lesion consistent with the acute central cord syndrome at C2-C3 level. Treatment with gallie method has shown lower fusion rate than screw rod construct. Patient underwent posterior atlantoaxial fusion with screw rod construct and was discharged with a good neurological improvement.
\end{abstract}

Keywords: Central cord syndrome, Fracture Dislocation, Dens fracture, skull traction, atlantoaxial fusion.

Introduction:

Paraparesis of the arms without paresis or paralysis of the legs after cervical spinal cord injury are rare. Acute central cord syndrome has rarely been associated with injury to the atlantoaxial complex with only a few case reports. ${ }^{3}$ Author report a rare case of selective paralysis after type II odontoid fracture with atlantoaxial dislocation. There are a few method for fixation, atlantoaxial fusion with gallie method has shown lower fusion rate in 3 months follow up than screw rod construct.

William Wiryawan et al /International Journal of PharmTech Research, 2019,12(2): 151-154.

DOI: http://dx.doi.org/10.20902/IJPTR.2019.120209 


\section{Case Report:}

Male, 32-years-old, complained about weakness of both upper limb, manual muscle testing revealed only trace movement of the shoulder and arm (2/5) whereas movement of both leg are better quality(4/5). Sensory testing showed loss of touch and pin prick sensation. Patient has no complain on his bladder function. His symptomps developed after he fell over while riding a motorcycle and hit his head upside down. Patient also complain about pain on his left shoulder and plain radiographs showed clavicle fracture and lateral border scapula fracture. Plain radiographs of the cervical spine showed traumatic $\mathrm{C} 1-\mathrm{C} 2$ posterolateral dislocation associated with odontoid fracture.

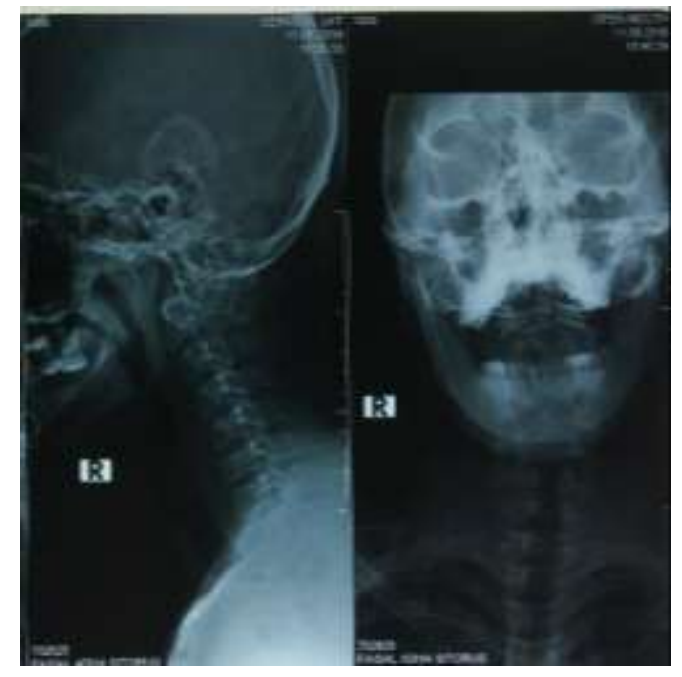

Fig 1. Plain Radiograph of the cervical spine shown fracture of the dens process of the axis
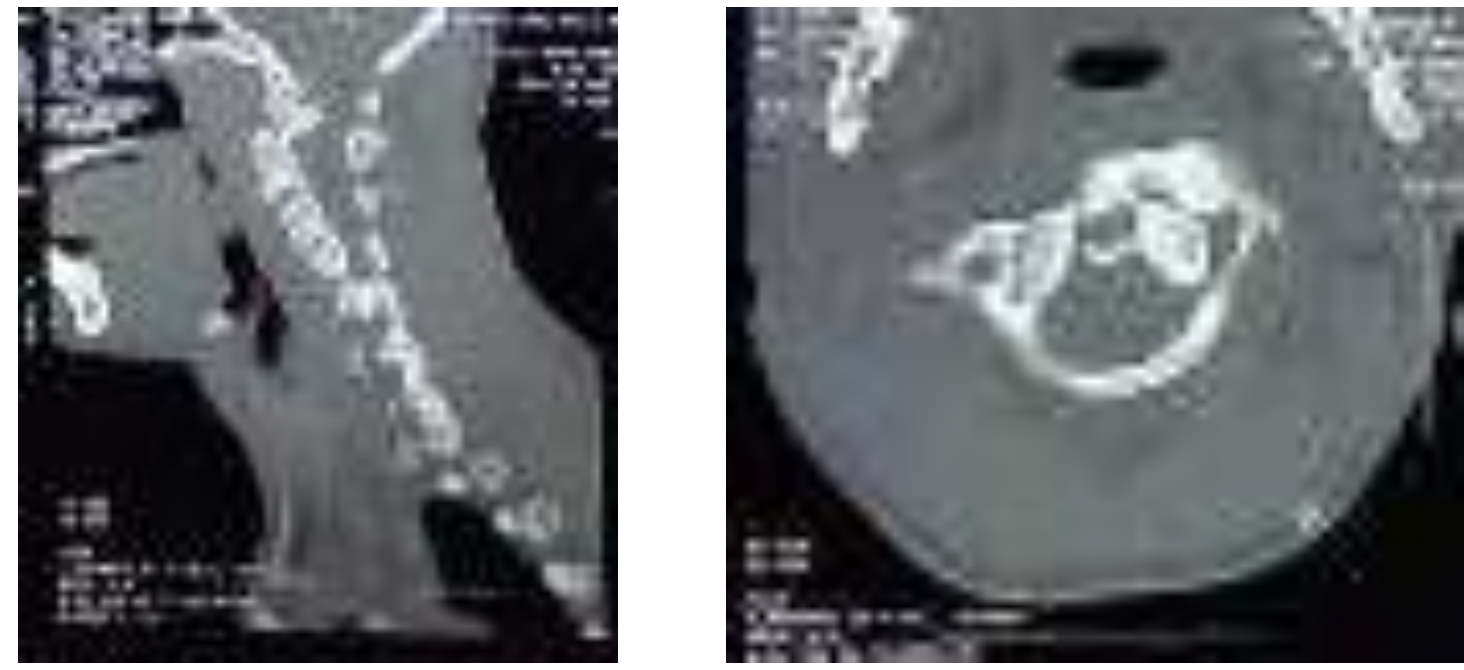

Fig 2. CT Scan of the cervical spine

Patient was done CT Scan and confirmed the odontoid fracture. A magnetic resonance imaging (MRI) scan revealed a posterior fracture dislocation $\mathrm{C} 1-\mathrm{C} 2$ compressing the spinal cord with cord oedema an intramedullary lesion length between $\mathrm{C} 2-\mathrm{C} 3$. 


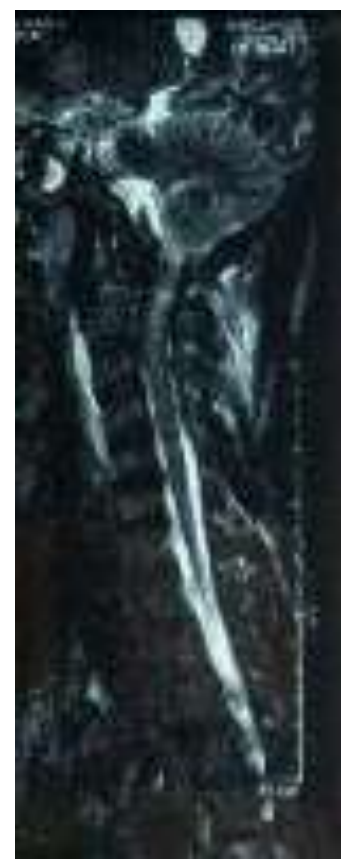

Fig 3. MRI of the cervical spine shown cord oedema on C2-C3

Patient was treated with skull traction using gardner well tongs traction, $4 \mathrm{~kg}$ was used as initial traction weight and patient shown a gradual improvement of his motoric and sensoric function. We continue the traction for 7 days and while maintaining skull traction, we performed atlantoaxial fusion with lateral mass fixation and put allograft (Demineralized bone matrix). We also performed ORIF on his left clavicle. Improvement of motoric function was recorded with ASIA grade D,1 month after the surgery. Improvement of motoric muscle power was recorded with upper motor (4/5) and normal muscle power on both leg (5/5). Sensoric function was seen improved but still felt a bit of numbness on his right arm.
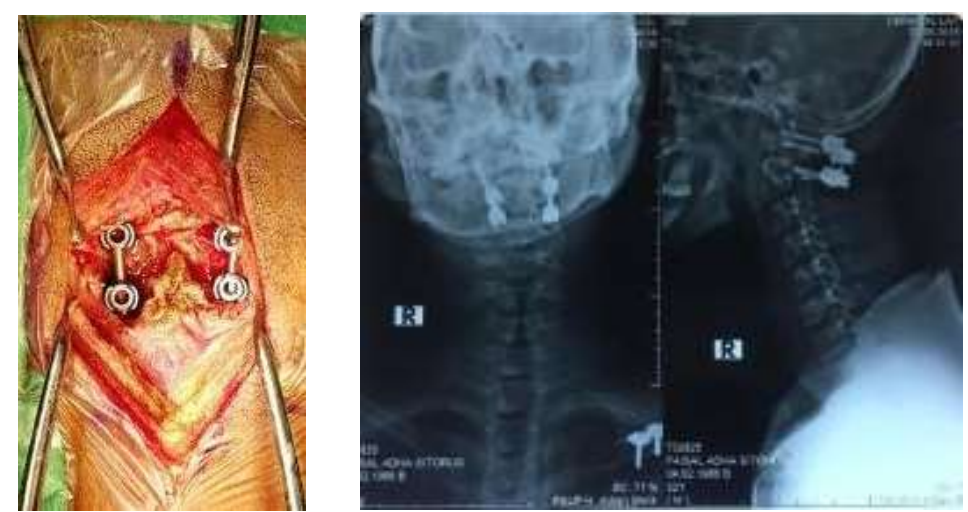

Fig 4. Atlantoaxial fusion was performed using screw-rod constuct

\section{Discussion:}

Odontoid fractures are the most common acute traumatic axis fracture. The incidence of neurological involvement after odontoid fractures has been reported around 27\%. Harrop et al described from 17 patient with odontoid fracture, only 4 had incomplete spinal cord injury. ${ }^{1}$ Treatment for type II dens fracture remain controversial, because lack of periosteum and cancellous bone and the presence in watershed area result in high incidence of nonunion (36\%). Dens fracture can be treated nonoperatively using halo traction, bone union was then obtained through the usage of halo vest for 3 to 6 months. Screw fixation of odontoid or C1- 
$\mathrm{C} 2$ posterior fusion may be required fo adequate treatment. ${ }^{2}$ Inamasu et al has described patient with odontoid fracture associated with central cord syndrome treated with posterior atlantoaxial fusion with titanium wire shown little functional recovery of the muscle strength. ${ }^{3}$ Patient underwent continuous skull traction for 1 week and continued with posterior fusion using screw rod construct. Yuan et al described from 49 patient with odontoid fracture, $88 \%$ of patient treated with gallie fusion achieve good bone fusion in 3 months where as patient treated screw rod construct have $100 \%$ fusion rate. ${ }^{4}$ The usage of allograft instead of autograft in atlantoaxial fusion reduced blood loss, operative time and donor site morbidity although study shown that allograft bone fusion takes longer (only 14\% cases appear fused at 6 months). ${ }^{5}$ Another study shown that clinical result and fusion rate with autograft and allograft have similar result, although they have noted that union in autograft occurred at 4 months after treatment, whereas in the allograft group occurred later, at 5.54 months after treatment. ${ }^{6}$ In this case, we have shown closed reduction followed with atlantoaxial fusion has shown good outcome.

\section{Conclusion:}

Odontoid fractures are the most common acute traumatic axis fracture. Incidence of incomplete spinal cord injury with odontoid fracture is rare. Timing of surgery in central cord syndrome remain a controversial. We have shown patient treated with skull traction and delayed surgery using screw rod construct has shown a good clinical outcome.

\section{References:}

1. Harrop et al. Epidemiology of Spinal Injury After Acute Odontoid Fractures. Neurosurgical Focus. 8(6): article 4, 2000, doi:10.3171/foc.2000.8.6.5.

2. Kenneth, A. E, Kenneth J.K, Joseph D.Z. Cervical Spine. Handbook of Fracture $5^{\text {th }}$ ed.. 2015. Wolster Kluwer. New York. 106-107

3. Inamasu et al. Selective Paralysis of The Upper Extremities After Odontoid Fracture Acute Central Cord Syndrome or Cruciate Paralysis. Clinical Neurology and Neurosurgery 103. 2001. 238 - 241, doi:10.1016/S0303-8467(01)00146-9.

4. Yuan et al. Gallie Technique Versus Atlantoaxial Screw-Rod Constructs in Treatment of Atlantoaxial Sagittal Instability: A Retrospective Study of 49 Patients. Journal of Orthopaedic Surgery and Research. 2017. 12: 105, doi:10.1186/s13018-017-0607-y.

5. Hillard et al. Use of Allograft Bone for Posterior C1-2 Fusion. Journal of Neurosurgery: Spine. 11. 2009. 396-401, doi:10.3171/2009.5.SPINE08662.

6. Kao FC et al. Maintenace of interbody space in one and two level anterior cervical body fusion: comparison of effectiveness of autograft, allograft and cage. Clinical Orthopaedics and Related Research. 430: 108-116, 2005, doi:10.1097/01.blo.0000142626.90278.9e. 